\title{
Onde e Como se Suicidam os Guarani e Kaiowá em Mato Grosso do Sul: Confinamento, Jejuvy e Tekoha
}

\author{
Pamela Staliano ${ }^{1}$ \\ Marcos Leandro Mondardo² \\ ${ }^{1}$ Universidade Federal da Grande Dourados, MS, Brasil. $\quad{ }^{2}$ Universidade Federal da Grande Dourados, MS, Brasil. \\ Roberto Chaparro Lopes ${ }^{3}$ \\ ${ }^{3}$ Universidade Federal da Grande Dourados, MS, Brasil.
}

Resumo: O território para os povos originários éfundamental para a saúde e reelaboração cultural de seus modos de ser, na relação entre natureza, cultura e relações de poder/resistência. O direito a viver ou morrer se liga à territorialidade na luta pela terra. O objetivo deste trabalho consistiu em analisar onde e como ocorrem os suicídios de Guarani e Kaiowá na contemporaneidade. Realizou-se uma pesquisa qualitativa de análise documental de reportagens veiculadas em jornais de maior circulação no estado de Mato Grosso do Sul. A busca foi realizada em 23 jornais, mas apenas 12 deles apresentaram notícias com a temática a partir da combinação dos descritores: Suicídio, Guarani, Kaiowá, Índio e Indígena. Constituiu-se uma amostra com 100 reportagens que informaram 105 ocorrências de suicídio no período entre 2002 a 2018. Os dados revelam que a violência é frequente nas reservas indígenas em que os Guarani e Kaiowá foram confinados no sul do estado. Os casos se concentram em aldeias dos municípios de Dourados e Amambai, a maioria entre jovens adultos com idade entre 12 e 22 anos, do sexo masculino. A eminente maioria (95\%) cometeu suicídio pela prática do enforcamento (jejuvy). As causas para o suicídio variam desde explicações orientadas pela cosmologia, o feitiço, formas culturais de morrer, desterritorialização de seus tekoha e a inserção econômica marginal. Considerando os dados alarmantes, sugere-se a criação e implementação do CAPS indígena, com o envolvimento de atores institucionais, como a Sesai e a Secretaria Municipal de Saúde, além de lideranças religiosas, Ñhanderu e Nhandecy.

Palavras-chave: Suicídio, Guarani, Kaiowá, Saúde, Tekoha. 


\section{Where and How the Guarani and Kaiowá Commit Suicide in Mato Grosso do Sul: Confinement, Jejuvy and Tekoha}

The territory for the native peoples is fundamental to the health and cultural re-elaboration of their ways of being, in the link between nature, culture and relations of power/resistance. The right to live or die is connected to territoriality in the struggle for land. The objective of this work was to analyze where and how the suicides of Guarani and Kaiowá occur in contemporary times. A qualitative research with documentary analysis of reports published in the newspapers with the largest circulation in the state of Mato Grosso do Sul was performed. The search was carried out in 23 newspapers, but only 12 of them presented news with the theme, combining the descriptors: Suicide, Guarani, Kaiowá, Indian and Indigenous. A sample of 100 reports that reported 105 suicide occurrences between 2002 and 2018 was composed. Data reveal that violence is frequent in the indigenous reserves where the Guarani and Kaiowá were confined in the south of the state. The cases are concentrated in villages in the municipalities of Dourados and Amambai, mostly among male young adults between 12 and 22 years of age. The eminent majority (95\%) committed suicide by the practice of hanging (jejuvy). The causes for suicide range from explanations guided by cosmology, the spell, cultural forms of dying, deterritorialization of their tekoha, and marginal economic insertion. Considering the alarming data, it is suggested the creation and implementation of indigenous CAPS, with the involvement of institutional actors, such as Sesai and the Municipal Health Secretariat, as well as religious leaders, Ñhanderu and Nhandecy.

Keywords: Suicide, Guarani, Kaiowá, Health, Tekoha.

\section{¿Dónde y Cómo se Suicidan los Guaraníes y Kaiowás en Mato Grosso del Sur: Confinamiento, Jejuvy y Tekoha}

Resumen: El territorio para los pueblos originarios es fundamental para la salud y reelaboración cultural de sus modos de ser, en la relación entre naturaleza, cultura y relaciones de poder/ resistencia. El derecho a vivir o morir se une a la territorialidad en la lucha por la tierra. El objetivo de este trabajo consistió en analizar dónde y cómo ocurren los suicidios de Guaraníes y Kaiowás en la contemporaneidad. Se realizó una investigación cualitativa de análisis documental de reportajes publicados en periódicos de mayor circulación en el estado de Mato Grosso do Sul. La búsqueda fue realizada en 23 periódicos, pero sólo 12 de ellos presentaron noticias con la temática a partir de la combinación de los descriptores: Suicidio, Guaraní, Kaiowá, Indio e Indígena. Se constituyó una muestra con 100 reportajes que informaron 105 casos de suicidio en el período entre 2002 y 2018. Los datos revelan que la violencia es frecuente en las reservas indígenas en que los Guaraníes y Kaiowás fueron confinados en el sur del estado. Los casos se concentran en aldeas de los municipios de Dourados y Amambai, la mayoría entre jóvenes adultos con edad entre 12 y 22 años, del sexo masculino. La eminente mayoría (95\%) cometió suicidio por la práctica del ahorcamiento (jejuvy). Las causas para el suicidio varían desde explicaciones orientadas por la cosmología, el hechizo, formas culturales de morir, desterritorialización de sus tekohas y la inserción económica marginal. Considerando los datos alarmantes, se sugiere la creación e implementación del CAPS indígena, con la participación de actores institucionales, como la Sesai y la Secretaría Municipal de Salud, además de líderes religiosos, Ñhanderu y Nhandecy.

Palabras clave: Suicidio, Guaraní, Kaiowá, Salud, Tekoha. 


\section{Introdução}

A saúde faz parte de uma agenda de luta para os povos indígenas. Em 1967 foi criada a Fundação Nacional do Índio (Funai), desde então esta área passou por diversas mudanças no seu processo de consolidação enquanto política pública, ficando por muito tempo sob os cuidados da Fundação Nacional de Saúde (Funasa) e, apenas em 2010, a partir de demandas e lutas do movimento indígena, foi criada a Secretaria Especial de Saúde Indígena (Sesai) que passou a assumir os cuidados com a saúde dos distintos grupos étnicos. Segundo Batista e Zanello (2016), a questão da saúde mental indígena passou a ganhar destaque nas mídias sociais e no meio acadêmico a partir da década de 1990, quando temáticas como o suicídio e o uso e abuso de álcool e outras drogas, passaram a chamar atenção da população e de pesquisadores da área.

Dados apresentados pelo Ministério da Saúde em 2017 demonstram que o Coeficiente de Mortalidade (CM) por suicídio entre os povos indígenas no Brasil foi quase três vezes maior que o $\mathrm{CM}$ por suicídio entre a população geral no país. Entre 2011 e 2015, o CM de suicídios entre a população brasileira foi de 5,5/100 mil hab., enquanto para as populações indígenas foi de 15,2/100 mil hab. A taxa de suicídios entre indígenas no Brasil é maior até mesmo que a taxa no mundo apresentada pela Organização Mundial da Saúde (OMS) em 2014, que era de 11,4/100 mil habitantes. O estado de Mato Grosso do Sul (MS), destaca-se a nível nacional por seus números elevados quanto às mortes de indígenas por suicídio. De acordo com o Ministério da Saúde (2017a), o CM por suicídio em MS, correspondente ao período de 2011 a 2015, foi de 8,5/100 mil hab., maior que a média nacional de 5,5/100 mil hab. para o mesmo período.

Os números elevados nos casos de suicídio registrados entre os Guarani e Kaiowá nas reservas indígenas da região sul de MS também chamam a atenção. A maioria dos casos de suicídios entre indígenas no estado ocorrem entre os Guarani e Kaiowá. Brand e Vietta (2001) consideram que entre os anos de 1981 e 2000 foram registrados 436 casos de suicídios destes povos no estado, sendo que os jovens adultos são os mais atingidos. Dos casos levantados pelo estudo, 225 estão entre pessoas de 12 a 21 anos, com incidência de 91 casos entre 15 a 18 anos.

Na década de 1990, os elevados números de suicídio entre indígenas, denominados por Morgado
(1991) e Brand \& Vietta (2001), como "Epidemia de Suicídio”, começaram a chamar atenção de pesquisadores, indigenistas e órgão públicos. Estudos foram realizados na tentativa de entender as causas que justificassem essa prática. Para os Guarani e Kaiowá a saúde está intimamente relacionada à questão da luta pela terra, que engloba desde a desterritorialização histórica de seus tekoha, à territorialidade compulsória vivida nas reservas e o movimento contemporâneo de reconhecimento de seus territórios tradicionais (Mondardo, 2018).

Propomos, nesse sentido, analisar a situação da saúde indígena, especificamente dos suicídios Guarani e Kaiowá, por meio do debate de território e territorialidade, na luta pela terra. Partindo desta problemática, abordaremos os conceitos de território e territorialidade e sua correlação com a vida e a morte dos Guarani e Kaiowá. Para o geógrafo Haesbaert (2004), cada campo do conhecimento (Geografia, Economia, Sociologia, Psicologia) aborda a dimensão territorial em seus estudos e apropria-se daquelas dimensões analíticas que se articulam mais consistentemente aos seus propósitos. Nesse contexto, Haesbaert apresenta quatro dimensões territoriais: 1) política (hegemônica e que vê o espaço delimitado/controlado, por meio do qual se exerce poder); 2) cultural (como produto de apropriação simbólico/ subjetiva por um determinado grupo em relação ao seu espaço vivido); 3) econômica (com a prioridade da dimensão espacial das relações econômicas, sendo visto como fonte de recursos e local de lutas entre classes sociais ou da relação capital versus trabalho); e 4) a naturalista (concepção de território animal de demarcação de espaço físico, e de ênfase entre as relações sociedade e natureza). Na tentativa de superar essa fragmentação, o autor propõe uma perspectiva integradora na qual o território é visto enquanto um continuum entre materialidade e subjetividade, funcionalidade e simbolismo, dominação e apropriação.

O território para os povos originários é fundamental para a produção de saúde e reelaboração cultural de seus modos de ser por meio da relação entre natureza, cultura e relações de poder/resistência. É importante ressaltar que as concepções e as modalidades de territórios e territorialidades entre os povos indígenas são muito variadas e distintas a depender dos grupos étnicos nas diversas regiões brasileiras. Por meio da problemática do território, a partir da luta pela terra, propormos analisar a saúde indígena con- 
siderando as práticas de suicídio entre os Guarani e Kaiowá no MS. Essa questão se tornou central no contexto brasileiro como um grave problema de saúde pública e que demanda estudos sérios e comprometidos para a construção de políticas específicas para esses grupos étnicos.

Segundo Haesbaert (2014), no Brasil contemporâneo podemos distinguir pelo menos duas formas geográficas de território, numa leitura mais ampla e não dualista, em que se desdobram pelo menos dois grandes "paradigmas" de abordagem das questões territoriais: 1) um que podemos denominar de hegemônico, dirigido, sobretudo pelas grandes empresas (com o frequente apoio do Estado), e outro 2), contra-hegemônico, liderado pelos grupos subalternos, em nosso caso, os povos e comunidades tradicionais (indígenas).

Tomando de empréstimo essas definições, abordaremos o território pelas relações de resistência dos povos, implicadas na própria luta pela terra, aliada aos processos de subjetivação dos grupos étnicos em reservas e acampamentos indígenas. Hoje, se por um lado muitos grupos de minorias sociais dependem do território enquanto espaço estratégico para lutar e resistir (Santos, 2007), por outro lado, os espaços dos povos indígenas também são produzidos no mundo pelas ações de precarização da vida, das violências sofridas, de desreterritorialização - o desfazer e refazer constante de territórios e territorialidades (Raffestin, 1993) -, em um regime de "Estado de insegurança" (Lorey, 2015) e/ou de "Estado de Exceção" (Agamben, 2004), e que afeta diretamente a saúde indígena.

Mondardo (2017) afirma que por meio do debate dos povos e populações tradicionais, o território é um direito que condensa formas de obter reconhecimento étnico e de conquistar ou ter acesso a direitos, tais como saúde, educação, alimentação, bem viver, segurança, terra, dentre outros. Por isso, o direito à saúde para os povos indígenas parte da defesa e fortalecimento de políticas públicas específicas para os grupos étnicos, e implica o reconhecimento das terras de uso e ocupação originária, como definida na Constituição Federal de 1988. O direito a viver está condicionado ao direito à saúde que se liga à luta pela terra para a demarcação dos antigos tekoha.

Além do território, a territorialidade, entendida neste trabalho como a multidimensionalidade do vivido (Raffestin, 1993), é um fator importante para a cosmologia e para a saúde dos povos indígenas. No MS indígenas vivenciam em sua territorialidade cotidiana a lógica do confinamento nas reservas, pequenos territórios demarcados pelo Estado. Entre os anos de 1915 a 1928, o Serviço de Proteção aos Índios criou oito pequenas áreas - reservas indígenas multiétnicas - que desterritorializou/expulsou os povos Guarani, Kaiowá e Terena (dentre outros grupos étnicos) por "despossessão" (Harvey, 2004), saque e/ou esbulho de suas terras de ocupação tradicional. Nesse período foram criadas respectivamente as reservas de Amambaí (1915), Dourados (1917), Caarapó (1924), Pirajuí (1928), Limão Verde (1928), Porto Lindo (1928), Sassoró (1928) e Taquaperi (1928).

Essa desterritorialização promoveu, de um lado, territorialidades de morte, a exemplo do crescente número de suicídios, e de outro, territorialidades de vida, por meio das lutas pela reterritorialização nos antigos tekoha. Nessa dinâmica espaçotemporal de negação da terra e do território para o indígena, desde a década de 1970 ocorreram movimentos de luta pela reterritorialização efetiva em seus tekoha. A partir da década de 2000, a problemática da regularização fundiária e o avanço do agronegócio sobre terras antes ocupadas por grupos étnicos têm influenciado diretamente nas formas de organização social.

Desde o surgimento da denominada "epidemia de suicídio entre os Guarani e Kaiowá", muitas causas ou "pseudocausas", como denomina Morgado (1991), são apontadas para justificar os altos índices de suicídio indígena. Essas causas transitam de explicações mais orientadas por aspectos da cosmologia de cada povo, o feitiço e formas culturais de morrer, até questões relacionadas à restrição territorial e a inserção econômica marginal que vivem os indígenas (Foti 2004; Guedes, 2015).

Destaca-se que profissionais de distintas áreas do conhecimento, como a Psicologia, a Antropologia, a Geografia e a Sociologia, estão realizando estudos, com interfaces teóricas interdisciplinares entre conhecimentos acadêmicos e práticas tradicionais que visam promover um diálogo de saberes (Leff, 2001). A gravidade e a complexidade contemporânea do suicídio, em que se destacam os números alarmantes nos estados do Amazonas e do Mato Grosso do Sul, tem se mostrado um desafio para pesquisadores, indigenistas e órgãos públicos.

Frente a esta questão de saúde dos povos indígenas, o objetivo deste texto consistiu em analisar onde e como ocorrem os suicídios de Guarani e Kaiowá na 
contemporaneidade. Para isso, realizou-se um levantamento diário e sistemático para a coleta de casos de suicídios em reportagens de jornais de circulação regional no MS.

\section{Método}

Este trabalho consistiu de uma pesquisa qualitativa de análise documental de reportagens veiculadas em jornais de maior circulação no estado de MS. O levantamento foi realizado entre agosto de 2018 a março de 2019, como desdobramento do projeto de pesquisa intitulado "Fronteiras e territórios: conceitos e práticas em áreas de insegurança".

As buscas não foram limitadas por período e o levantamento foi organizado nas seguintes etapas:

1. A busca foi realizada em 23 jornais $^{1}$ de abrangência regional de maior circulação no estado, com a combinação dos descritores utilizados: Suicídio, Guarani, Kaiowá, Índio e Indígena, sendo que foram encontradas reportagens em 12 deles: Amambai Notícias, Campo Grande News, Conesul News, Correio do Estado, Diário Digital, Dourados Agora, Dourados News, Douranews, Fátima News, Midiamax, O Progresso e Ponta Porã Informa.

2. Exclusão de notícias duplicadas.

3. Elaboração de uma tabela para a sistematização dos dados com as seguintes informações: fonte, número de óbitos, data/ano da ocorrência, município, local da ocorrência, etnia, breve descrição do caso, idade das vítimas e link das notícias.

4. Classificação e categorização das notícias.

Percorrendo as etapas para o levantamento do material, as primeiras buscas identificaram um total de 11.381 reportagens, das quais 132 relatavam casos de suicídios de indígenas no estado. Destas, 32 notícias eram de casos repetidos e foram excluídas. Assim, foi reunida uma amostra de 100 reportagens que informavam 105 registros de suicídios entre indígenas.

A última etapa do delineamento metodológico consistiu em realizar uma categorização a partir da leitura cuidadosa das reportagens que compõem a amostra. Este procedimento respeitou os passos da técnica de análise de conteúdo propostos por Bardin (2008): 1) pré-análise; 2) exploração do material;
3) tratamento dos dados, inferência e interpretação. Com isso foram criadas três categorias: 1 . Suicídio por enforcamento; 2. Suicídio por arma de fogo; e 3. Suicídio por envenenamento.

\section{Resultados e discussão}

A partir da busca empreendida nos jornais, com a utilização dos descritores informados, 100 reportagens foram identificadas. Destas, cinco noticiaram duas mortes por suicídio, assim, tivemos 105 casos no período de 2002 a 2018.

O jornal que foi encontrado o maior número de reportagens, representando $32,4 \%(\mathrm{n}=34)$ foi $\mathrm{o}$ Dourados News, seguido por Dourados Agora 16,2\% $(\mathrm{n}=17)$, Midiamax 15,2\% $(\mathrm{n}=16)$, Campo Grande News, 10,5\% ( $\mathrm{n}=11)$, Fátima News, 6,6\% $(\mathrm{n}=7)$ Correio do Estado, 4,8\% ( $\mathrm{n}=5)$, Douranews, 3,8\% $(\mathrm{n}=4)$, Ponta Porã Informa, 3,8\% ( $=4)$, O Progresso, 2,8\% $(\mathrm{n}=3)$, Diário Digital, $1,9 \%(\mathrm{n}=2)$, Cone Sul News $1 \%$ $(\mathrm{n}=1)$ e Amambai News 1,0\% ( $\mathrm{n}=1)$. O Quadro 1 apresenta o número de casos de suicídio por município e local da ocorrência.

A presente pesquisa aponta os municípios de Dourados e Amambai com os maiores números de ocorrências, $40 \%$ e 21\%, respectivamente. Os Relatórios de violência contra os povos indígenas do Conselho Indigenista Missionário (CIMI), no período de 2003 a 2013, evidenciam dados bem parecidos, sendo possível identificar que Dourados é o município do estado que mais se destaca negativamente quanto aos números de casos de suicídio. Dos 234 indígenas Guarani e Kaiowá que tiraram a própria vida em Mato Grosso do Sul, 78 casos ocorreram em Dourados (33,3\%). Em média, quase oito Guarani e Kaiowá se suicidam por ano em Dourados (CIMI, 2006, 2008, 2009, 2010, 2011, 2012, 2013, 2014).

Amambai também aparece como o segundo município com maior número de óbitos nos relatórios do CIMI no período de 10 anos. Com 51 dos 234 casos de suicídio dos Guarani e Kaiowá, o município registrou 21,7\% de todos os suicídios destes povos em Mato Grosso do Sul. A média de suicídios entre os Guarani e Kaiowá no município é de aproximadamente cinco por ano. Nos municípios de Dourados e Amambai foram identificados $41 \%$ das mortes por lesões auto-

${ }^{1}$ Amambai Notícias, Caarapó News, Caarapó Online, Campo Grande News, Caribel News, Conesul News, Correio do Estado, Diário Digital, Diário MS, Dourados Agora, Dourados News, Douranews, Fátima News, Fronteira News, Jornal do Cone Sul, Midiamax, MS em Foco, O Progresso, Ponta Porã Informa, Portal do Cone Sul, Portal do MS, Portal Top Mídia News e Sidrolândia News. 
Quadro 1

Casos de suicídio por município e local informado nas reportagens.

\begin{tabular}{|lcc|}
\hline Município & Local & Número de Óbitos \\
\hline \multirow{3}{*}{ Dourados } & Aldeia Bororó & 30 \\
Amambai & Aldeia Jaguapiru & 9 \\
& Aldeia Panambizinho & 3 \\
Caarapó & Aldeia Amambai & 16 \\
Coronel Sapucaia & Aldeia Limão Verde & 6 \\
Japorã & Aldeia Tey Kuê & 8 \\
& Aldeia Guyraroká & 1 \\
Paranhos & Aldeia Taquaperi & 6 \\
& Aldeia Porto Lindo & 4 \\
Douradina & Aldeia Pirajuí & 1 \\
& Aldeia Arroio-Korá & 1 \\
Tacuru & Aldeia Potrero Guaçu & 2 \\
Ponta Porã & Aldeia Paraguassu & 1 \\
Antônio João & Aldeia Panambi* & 2 \\
Rio Brilhante & Aldeia Lagoa Rica & 2 \\
Juti & Aldeia Sassoró & 2 \\
Sete Quedas & Aldeia Jaguapiré & 1 \\
Eldorado & Sanga Puitã & 1 \\
Itaporã & Aldeia Lima Campo & 1 \\
\hline A & Aldeia Campestre & 1 \\
\hline
\end{tabular}

*A Aldeia Panambi está localizada entre os municípios de Douradina e Itaporã.

provocadas entre os Guarani e Kaiowá no Brasil (CIMI, 2006, 2008, 2009, 2010, 2011, 2012, 2013, 2014).

A violência é presente e frequente nas reservas indígenas em que os Guarani e Kaiowá foram confinados no sul do estado. Essas manifestações de violência se fundem aos elevados índices de mortalidade que as áreas indígenas em Mato Grosso do Sul apresentam, inclusive nas altas taxas de suicídios. Os fenômenos de violência permitem afirmar que se coloca em prática uma lógica necropolítica (Mbembe, 2011) de eliminação/extermínio do Outro pelos suicídios e assassinatos cometidos contra estes povos originários.

Evidencia-se muitas vezes a violência "institucional" e a violência "étnica e cultural" que o povo Guarani e Kaiowá sofreu e, ainda hoje, sofre de forma aguda, por parte do Estado brasileiro, e, em muitas das vezes, na relação deste com o grande capital agrícola (nacional e internacional), personificado de forma mais radical na figura dos fazendeiros, políticos, comerciantes, e de empresas como frigoríficos, usinas, dentre outras.

Em 2016, em uma matéria de jornal, indígenas alegaram sofrer um "genocídio psicológico" por parte do Estado brasileiro. A matéria relata o despejo de um grupo de indígenas de uma fazenda, próxima a Dourados, que foi ordenada pela Justiça Federal e cumprida pela Polícia Federal. Sem ter para onde ir, muitos indígenas ficaram na beira da estrada, inclusive crianças e bebês de colo (Freitas, 2016).

De acordo com Mondardo (2018), a relação conflituosa existente entre fazendeiros e indígenas tem 
como base a disputa pela terra e o reconhecimento dos territórios tradicionais. Para os Guarani e Kaiowá a terra significa muito mais do que o lugar "onde se planta" ou a simples relação entre "plantar e colher", eles possuem uma ligação sagrada com a terra, uma ligação com os ancestrais e seus espíritos. Por isso, quando foi tomada dos indígenas a terra e os cerraram em pequenas áreas, foi desorganizado/precarizado o seu modo de vida (teko) por meio da desterritorialização de seus tekoha, o que limitou a sua relação cultural com a natureza. Os territórios tradicionais são aqueles espaços de organização das famílias extensas, das relações de parentesco, da religiosidade, do forte apego (pertencimento) à terra, da relação entre a vida e a morte, entre humano e não humano, conforme a sua cosmologia.

Diante deste contexto de destituição territorial, Morgado (1991) argumenta que os casos de suicídio entre os Guarani e Kaiowá podem ser melhores explicados pela hipótese do recuo do impossível, que ocorre a partir de dois tipos de sujeição do indivíduo:

1) Total esgotamento de opção para recuar ou mudar, sem nenhuma possibilidade de território para os indígenas viverem, enquanto povo com identidade própria. Até recentemente podia-se recuar; agora, isso acabou, e para sempre; 2) Degradação extrema de condições universais de dignidade do ser humano, que independe da pessoa ser um indígena ou não; liquidar o patrimônio material e cultural, corromper os costumes e aviltar a pessoa é ruim para qualquer grupo de indivíduos (Morgado, 1991, p. 592).

Dessa forma, muitos creditam o "fator tekoha" como um ingrediente para o crescimento das mortes por suicídio dos Guarani e Kaiowá em MS. Em seus territórios sagrados, este povo pode praticar o teko, que é o "modo de ser" Guarani com seus costumes, crenças, rituais e práticas de subsistência, o que hoje na maioria das vezes é limitante ou insuficiente. "Estamos espremidos entre a soja, a cana e a estrada, vivendo em barracos de lona sem ter o que comer. Estamos jogados na beira da estrada como lixo", desabafou um líder indígena a um jornal (Zinet, Tupinambà, \& Cabral, 2012).

A problemática da terra interfere diretamente na vida de cada um dos indígenas Guarani e Kaiowá, vivam eles nas reservas, acampamentos de retomada ou mesmo nas cidades. Atualmente, eles estão confinados em pequenas áreas, na maioria das vezes distantes dos tekoha originários, e se veem ameaçados por inúmeros fatores que colocam em risco a manutenção de suas tradições e até mesmo de sua existência.

Em nossa pesquisa, com relação à idade da vítima foi possível identificar que a maioria dos casos ocorre entre adultos $54 \%(n=57)$, com idade variando de 20 a 59 anos, com média de 30 anos. Entre os jovens com idade entre 13 a 19 anos, com média de 16 anos, o percentual de casos representa $44 \%(n=46)$, e apenas dois casos de suicídio entre idosos, sendo duas senhoras, uma de 68 e outra de 71 anos. Assim, aproximadamente $66 \%$ dos casos noticiados são entre jovens adultos entre 12 e 22 anos. Dos casos em que é possível identificar o sexo das vítimas, $76 \%$ são homens, com idade média de 23 anos. Estes dados convergem com os resultados dos estudos realizados anteriormente por Brand e Vietta (2001), que também identificaram as maiores taxas de suicídio entre os jovens adultos no período de 1981 a 2000.

Considerando as categorias de suicídio criadas neste estudo, a eminente maioria consiste em suicídio por enforcamento, o que representa aproximadamente $95 \%$ dos casos noticiados $(n=100)$. Nestas ocorrências os materiais mais usados para se pendurarem em árvores e no interior de suas residências são: corda, pano, cadarço, cordão, cinto, fio, alça de bolsa. Alguns destes objetos utilizados pelos indígenas evidenciam a precariedade no enforcamento e parecem demonstrar certo desespero no ato, pois todo e qualquer objeto que é passível de ser envolvido no pescoço e cause "asfixia mecânica", "constrição cervical" ou "enforcamento", tornaram-se "armas" letais. No Quadro 2 é possível verificar uma breve descrição de alguns destes casos de suicídios.

As outras duas categorias foram: suicídio por arma de fogo $3 \%(n=3)$, sendo que os três casos atiraram em sua "barriga", e suicídio por envenenamento $2 \%(n=2)$, com a ingestão de agrotóxico. Tanto a morte por arma de fogo quanto por envenenamento simboliza os instrumentos presentes nos conflitos territoriais que envolvem indígenas e fazendeiros. A arma é um objeto de poder dos fazendeiros e frequentemente usado nos conflitos, e o agrotóxico/pesticida faz parte e/ou é necessário à produção em larga escala do agronegócio. Podemos observar o detalhamento destes casos no Quadro 3. 


\section{Quadro 2}

Casos de suicídio por enforcamento dos Guarani e Kaiowá.

"o indígena se enforcou com um cordão do short, se pendurando em um galho de árvore a 300 metros da casa dele" (Dourados News, 2006, Caarapó, Aldeia Tey Kuê, 16 anos, masculino).

"O pai dela entrou no barraco e se deparou com o corpo da jovem suspenso por um pedaço de pano preso a um galho que dá sustentação ao teto” (Diário Digital, 2014, Dourados, Aldeia Bororó, 21 anos, feminino).

"O corpo estava com uma corda amarrada no pescoço e em uma árvore alta" (Dourados News, 2011, Dourados, Aldeia Panambizinho, 13 anos, feminino).

“o indígena usou a alça de uma bolsa de nylon para se enforcar" (Dourados News, 2007, Dourados, Aldeia Bororó, 21 anos, masculino).

“o indígena teria usado um cadarço para se enforcar” (Dourados News, 2007, Dourados, Aldeia Bororó, 17 anos, masculino).

"foi encontrado (...), enforcado em uma árvore às margens de uma estrada vicinal que corta a reserva" (Fátima News, 2013, Dourados, Aldeia Bororó, 15 anos, masculino).

"estava com uma corda improvisada com camisetas amarrada ao pescoço" (Dourados Agora, Japorã, Aldeia Porto Lindo, 18 anos, masculino).

"passou seu próprio cinto pelo pescoço e o amarrou em uma goiabeira, enforcando-se" (Dourados News, 2011, Paranhos, Aldeia Paraguassu, 19 anos, masculino).

"um primo (...) saiu no quintal viu a adolescente pendurada com um pedaço de lençol no pescoço" (Midiamax, 2010, Ponta Porã, Sanga Puitã, 13 anos, feminino).

"O garoto se enforcou usando uma corda feita com panos entrelaçados presa no teto da casa onde morava" (Campo Grande News, 2010, Sete Quedas, 14 anos, masculino).

Organização dos autores.

\section{Quadro 3}

Casos de suicídio por arma de fogo e envenenamento dos Guarani e Kaiowá.

"se matou [...] depois de ingerir uma certa quantidade de Tamaron, pesticida usado no combate a lagarta da soja" (Dourados News, 2003, Dourados, 55 anos, masculino).

Organização dos autores.

O suicídio é um fenômeno antigo entre os Kaiowá. Há cerca de 500 anos o missionário jesuíta peruano Antonio Ruiz de Montoya já relatava casos de enforcamentos e suicídios entre indígenas da etnia (Foti, 2004).

Para os Guarani existe um significado subjacente ao ato suicida, o jejuvy, como os próprios indígenas o chamam. Na concepção Guarani, no nascimento o indígena ganha a companhia de dois pássaros sagrados e protetores: Mokoye Gwyra, que guardam o Ayvu, a força que move a alma do homem, a vontade de vida, e garantem uma boa vida e morte tranquila. Ao fim da vida, os pássaros retornam ao Cosmos, cumprindo sua missão. Entretanto, em vida, certas coisas podem afugentar os pássaros protetores, como violência, brigas, discussões, sentimentos de desesperança e também a ausência das terras sagradas - tekoha. Afugentados, algumas vezes eles voltam, outras não. Na ausência dos pássaros, os espíritos malignos que estão sempre à espreita, como o Angué, podem assumir o controle das ações desta pessoa, levando-as a cometerem 
ações que não fariam sem a presença deste espírito, entre elas o Jejuvy (Nolen, 2017).

Nessa perspectiva o jejuvy é o ato do enforcar-se, já o Angué é o espírito maligno. O Angué se abriga na garganta da pessoa, despertando nela a vontade do Jejuvy, principalmente pelas maneiras que usam a garganta para se chegar ao suicídio. No campo linguístico Guarani, a palavra Jejuvy representa "aperto na garganta”, sufocação (Foti, 2004, p. 9). Assim:

"O Jejuvy é um ato complexo, um ato individual, individualizante, mas que obedece a uma forte motivação cultural, um exemplo da marca do coletivo na experiência mais íntima dos indivíduos, mesmo tratando-se, por hipótese, de um ato antissocial, em volta do qual observa-se muita dor e consternação" (Foti, 2004, p. 10).

No Jejuvy todos os atos suicidas são materializados no tórax e garganta, seja através da ingestão de veneno, pelo enforcamento ou pela asfixia (Meihy, 1991). Um detalhe interessante que acompanha alguns dos casos de Guarani e Kaiowá que tentaram o suicídio e não obtiveram êxito é uma forma de "esquecimento" e de não compreensão da tentativa no momento. Foti $(2004$, p. 9) chama atenção ainda para o "imediatismo" das decisões dos indígenas em sanar a própria vida, que em muitas das vezes se dá de forma abrupta e momentânea.

Uma vez no tekoha, o espírito Anguése espalha de pessoa em pessoa, indo a outros tekoha e espalhando sofrimento e uma onda de Jejuvy, que os curandeiros e líderes religiosos tentam parar através de rituais de proteção. E o que poderia afugentar Mokoy e Gwyra dos tekoha Guarani e Kaiowá? O contexto espaçotemporal que envolve o grupo étnico na contemporaneidade desencadeia essa realidade suicida por meio da precariedade e das violências sofridas (Foti, 2004; Nolen, 2017).

Frente a toda violência, adversidade, luta, dor, consternação, estes povos indígenas têm se mostrado resilientes. Ponderando juntamente com Dunker (2017), a concepção que as pessoas possuem sobre a morte e como lidam com ela pode tornar os processos de adoecimento mais penosos ou aumentar a resiliência. Nas ciências humanas este termo tem sido aplicado para referenciar a capacidade que as pessoas, grupos ou comunidades apresentam para superarem as adversidades ou traumas e saírem fortalecidas das mesmas. A resiliência envolve vários aspectos, dentre eles os psicológicos, físicos e fisiológicos.

Assim, a resiliência engloba fatores de proteção (influências que podem modificar ou melhorar a resposta a uma adversidade) e fatores de risco (podem aumentar a probabilidade de desadaptação) (Dunker, 2017). Neste contexto, a religiosidade para os Guarani e Kaiowá se apresenta como uma função protetora importante, na qual busca explicações para o suicídio e também na qual se apega, para superar a experiência de morte de um parente.

O Ministério da Saúde (Brasil, 2017b) considera que outro fator de proteção importante é a política de saúde mental. Dados confirmam que em municípios que contam com a presença de Centros de Atenção Psicossocial (CAPS), o risco de suicídio reduziu em $14 \%$. Existem no país, 2.462 CAPS, e em Mato Grosso do Sul, 146 unidades. Chama-se atenção para importância das políticas públicas na prevenção ao suicídio. No entanto, para isso é preciso melhorar as políticas e proteger as populações mais expostas. Considerando os casos alarmantes de suicídios entre os povos Guarani e Kaiowá, faz-se necessário que seja implantado CAPS nos territórios das reservas indígenas, a exemplo dos Centros de Referência da Assistência Social (CRAS).

Atualmente, quando os indígenas precisam de atendimento ou intervenção psiquiátrica, esta é realizada nos ambulatórios de saúde mental nos hospitais ou nos CAPS localizados nos municípios próximos às reservas. Nestes locais os povos tradicionais recebem atendimento como os não índios, sem considerar, portanto, questões relacionadas à especificidade étnica ou cosmologia do grupo. É necessária a ampliação da política pública, com a oferta dos serviços nos territórios onde habitam os indígenas, com uma atenção em saúde que valorize os aspectos culturais da realidade destas populações, com a presença e diálogo de saberes, inclusive, das lideranças religiosas, Ñhanderu e Nhandecy.

Guedes (2015) afirma que tanto a redução territorial quanto a inserção econômica marginal a que os indígenas estão expostos, são fatores que podem justificar alguns casos de suicídio. Para Mondardo (2013), a pobreza e as condições desumanas em que vivem muitos indígenas nas reservas, bem como a insegurança nos acampamentos de retomadas, são apontadas como condições que estão diretamente ligadas ao processo histórico de desterritorialização étnica sofrida. Mui- 
tos vivem na extrema pobreza, morando em barracos, tanto nas reservas quanto às margens de rodovias, que abrigam muitas vezes numerosas famílias, que lutam até mesmo para ter o que comer. Com isso, verifica-se a violência promovida contra os Guarani e Kaiowá pelo "racismo de Estado" (Foucault, 2002).

Confinados nas reservas ou territorializados precariamente em acampamentos às margens de rodovias, uma parcela de Guarani e Kaiowá vive sem condições mínimas de cidadania. Meihy (1991, p. 281) compreende o grande número de suicídios entre os Guarani e Kaiowá como algo mais "altruísta" do que "egoísta". Para o autor estas mortes podem ser vistas por meio de um "princípio motivador" e não se configuram como isoladas. A motivação pode ser um clamor de socorro, "uma prova de vitalidade do grupo" perante as condições dolorosas de vida que esses povos vivenciam e que escolhe, assim, "usá-lo como argumento político":

Produto das tensões internas de convívio e da pressão externa, as tribos atenderiam aos estímulos e reagiriam. A aceitação do suicídio como estímulo, portanto, convida a supor uma luta de grupos que querendo viver, se valem do contingente disponivel, em termos de mortes autoprovocadas, para se comunicar. Isto reforça o princípio que mostra os suicídios como derivados de fatores que enlaçam razões materiais, cósmicas, éticas e políticas. Neste sentido, a morte deste "exército de Reserva" é uma prova de vitalidade do grupo que opta por usá-lo como argumento político (Meihy, 1991, p. 281) [Grifos nossos].

Dessa forma, pode-se olhar também a situação atual dos Guarani e Kaiowá em MS como resultado de um governo bio/necropolítico (Foucault, 2004; Mbembe, 2011) praticado pelo Estado brasileiro nos últimos anos, aliada ao processo de acumulação capitalista no regime neoliberal (Harvey, 2004). No caso destas populações tradicionais, muitas vezes, a violência contra os povos indígenas tem partido de quem deveria protegê-las: o Estado.

Com a tomada das terras da América do Sul pelos europeus, muitos indígenas foram escravizados ao longo do processo de colonização. Morais (2016) considera ainda como os Guarani e Kaiowá do estado foram explorados no início do século passado na produção de erva-mate para a Companhia Matte Laran- jeiras, e ainda o trabalho que muitos realizavam nas usinas de açúcar do estado, principalmente durante a década de 1990. Atualmente, a mão de obra indígena é usada, em sua maioria, em trabalhos braçais em lavouras, na construção civil e em frigoríficos. Entretanto, a necessidade de qualificação profissional e o uso de tecnologias, além do racismo e do preconceito, erguem barreiras simbólicas e concretas que dificultam a inserção destes povos no mercado de trabalho, o que consequentemente leva a formação de um "exército de reserva".

Para Hilário (2016), a lógica capitalista tende a desqualificar determinada parcela da população quando esta não mais apresenta uma força de trabalho que possa vir a ser útil para o sistema. Este processo de desqualificação ocorre por meio do desemprego, abrigando essa parcela da população em periferias, prisões ou apenas aniquilando-as pelo uso da força policial. Esta política de aniquilação, ou necropolítica (Mbembe, 2011), tende a exterminar as forças de trabalho que não são mais vistas como rentáveis ao processo de acumulação capitalista.

Pensar nesta política de aniquilação pode fazer sentido quando se observa o contexto espaçotemporal dos Guarani e Kaiowá. Esses povos tiveram suas terras originárias saqueadas, foram confinados em pequenas áreas de reserva definidas pelo Estado, e atualmente, muitos vivem em condições de extrema pobreza, como analisamos. Somado a isto, verifica-se as tensões recorrentes desencadeadas pelos conflitos por terra, a incerteza jurídica que envolve a questão da regularização fundiária dos territórios em que habitam, e o clima de ameaças que rondam e a insegurança em que vivem nas reservas e acampamentos. As violências que sofrem são físicas, simbólicas, jurídicas e epistêmicas, seja por meio de ameaças ou agressões sofridas por pistoleiros, forças políticas do Estado, ordens de despejo, preconceito, racismo, atropelamentos, enforcamentos, dentre outros.

\section{Considerações finais}

O suicídio entre os povos Guarani e Kaiowá é um fenômeno grave e complexo. Este ato praticado entre os indígenas é influenciado por questões históricas, cosmológicas e territoriais, inerentes à própria luta contemporânea para viverem o teko (modo de vida, territorialidade) nos territórios de ocupação tradicional (tekoha). Historicamente, a desterritorialização promovida pelo confinamento em reservas, o habi- 
tar forçado de inúmeras famílias em pequenas áreas demarcadas pelo Estado, impedindo a produção de saúde e a propagação de seu modo de ser, tem contribuído para questões mais contemporâneas, como a falta de perspectiva de vida e produtiva nas reservas, a luta pela terra e os conflitos territoriais com os fazendeiros. Assim, tanto as questões históricas quanto contemporâneas evidenciam as dimensões da vida, morte e territorialidade associadas à cosmologia, 0 que inclui o jejuvy.

Nossa pesquisa revelou que a maioria dos indígenas que cometem suicídio são jovens adultos do sexo masculino, com maiores concentrações nas reservas indígenas de dois municípios do estado: Dourados (40\%) e Amambai (21\%). O suicídio por enforcamento (jejuvy), uma prática antiga entre os Kaiowá, é a categoria mais evidente (95\%), seguido por outras duas formas bem menos incidentes, suicídio por arma de fogo (3\%) e por envenenamento (2\%). Em que medida pode-se pensar que a prática por enforcamento se relaciona simbolicamente ao ato de calar-se, por não ter voz, não ser ouvido, ser marginalizado e invisibilizado?

Considerando os dados alarmantes de suicídios indígenas em Mato Grosso do Sul que esta pesquisa revelou e que já vinha sendo demonstrado por estudos anteriores e denunciado como genocídio coletivo por lideranças indígenas e entidades indigenistas, ressalta-se a necessidade de políticas públicas afirmativas com equipes multidisciplinares, com o envolvimento de diversos segmentos da sociedade (indígenas e não indígenas) e de pesquisadores de distintas áreas para promover um diálogo de saberes, como os psicólogos, no enfrentamento dessa questão de saúde de populações indígenas expostas, como os Guarani e Kaiowá.

Nesta perspectiva, sugere-se a criação e implementação do CAPS indígena, com o envolvimento de atores institucionais, como a Sesai e a Secretaria Municipal de Saúde, além de lideranças religiosas, representados pelos Ñhanderu (rezador) e Nhandecy (rezadora). Propõe-se, com isso, que os indígenas não sejam submetidos aos tratamentos administrados e intervenções orientadas aos não índios, mas que haja a valorização do conhecimento tradicional, dos rituais, respeitando a cosmologia de cada povo. Ressalta-se a necessidade de reconhecer a diversidade cultural destes povos e a sua dinâmica no tempo e no espaço, isto é, "escutar" os Guarani e Kaiowá para entender a atender as suas demandas por saúde, terra e território.

\section{Referências}

Agamben, G. (2004). Estado de exceção. São Paulo, SP: Boitempo.

Bardin, L. (2008). Análise de conteúdo. Lisboa: 70.

Batista, M. Q., \&Zanello, V. (2016). Saúde mental em contextos indígenas: Escassez de pesquisas brasileiras, invisibilidade das diferenças. Estudos de Psicologia (Natal), 21(4), 403-414. https://doi.org/10.5935/1678-4669.20160039

Brand, A., \&Vietta, K. (2001). Análise gráfica das ocorrências de suicídios entre os Kaiowá/Guarani, no Mato Grosso do Sul, entre 1981 e 2000. Tellus, 1(1), 119-132. https://doi.org/10.20435/tellus.v0i1.18

Brasil. Ministério da Saúde. (2017a). Boletim Epidemiológico: Perfil epidemiológico das tentativas e óbitos por suicídio no Brasil e a rede de atenção à saúde. Brasília, DF: o autor.

Brasil. Ministério da Saúde. (2017b). Taxa de suicídio é maior em idosos com mais de 70 anos e indígenas. Brasília, DF: o autor. Recuperado de http://portalms.saude.gov.br/noticias/svs/29692-taxa-de-suicidio-e-maior-em-idosos-com-mais-de-70-anos

Conselho Indigenista Missionario - CIMI. (2006). A Violência contra os povos indígenas no Brasil: Relatório 20032005. Brasília, DF: o autor.

Conselho Indigenista Missionario - CIMI. (2008). Violência contra os povos indígenas no Brasil: Relatório 20062007. Brasília, DF: o autor.

Conselho Indigenista Missionario - CIMI. (2009). Violência contra os povos indígenas no Brasil: Relatório 2008. Brasília, DF: o autor.

Conselho Indigenista Missionario - CIMI. (2010). Violência contra os povos indígenas no Brasil: Relatório 2009. Brasil.

Conselho Indigenista Missionario - CIMI. (2011). Relatório violência contra os povos indígenas no Brasil: Dados de 2010. Brasília, DF: o autor. 
Psicologia: Ciência e Profissão 2019 v. 39 (n.spe)., e221674, 9-21.

Conselho Indigenista Missionario - CIMI. (2012). Relatório violência contra os povos indígenas no Brasil: Dados de 2011. Brasília, DF: o autor.

Conselho Indigenista Missionario - CIMI. (2013). Relatório violência contra os povos indígenas no Brasil: Dados de 2012. Brasília, DF: o autor.

Conselho Indigenista Missionario - CIMI. (2014). Relatório violência contra os povos indígenas no Brasil: Dados de 2013. Brasília, DF: o autor.

Dunker, C. (2017). Reinvenção da intimidade: Políticas do sofrimento cotidiano. São Paulo, SP: Ubu. (Trabalho original publicado em 1966).

Foti, M. V. (2004). A morte por jejuvi entre os Guarani do sudoeste brasileiro. Revista Estudos e Pesquisas, 1(2), 45-72.

Foucault, M. (2002). Em defesa da sociedade. São Paulo, SP: Martins Fontes.

Foucault, M. (2004). Naissance de la biopolitique. Paris: Gallimard-Seuil.

Freitas, H. (2016). Índios acusam de 'genocídio psicológico' por despejo em Dourados. Campo Grande News, interior. Recuperado de https://www.campograndenews.com.br/cidades/interior/indios-acusam-governo-de-genocidio-psicologico-por-despejo-em-dourados

Guedes, C. (2015). Suicídio indígena e exclusão social. Congresso Associação Latino-Americana de Sociologia ALAS, San Jose, Costa Rica, 30.

Haesbaert, R. (2004). O mito da desterritorialização: Do "fim dos territórios" à multiterritorialidade. Rio de Janeiro, RJ: Bertrand Brasil.

Haesbaert, R. (2014). Viver no limite: Território e multi/transterritorialidade em tempos de in-segurança e contenção. Rio de Janeiro, RJ: Bertrand Brasil.

Harvey, D. (2004). O novo imperialismo. São Paulo, SP: Loyola.

Hilário, L. C. (2016). Da biopolítica a necropolítica: Variações foulcaultianas na periferia do capitalismo. Sapere Aude, 7(12), 194-210. https://doi.org/10.5752/P.2177-6342.2016v7n13p194

Leff, E. (2001). Epistemologia ambiental. São Paulo, SP: Cortez.

Lorey, I. (2015). State of insecurity: Government of the precarious. London: Verso.

Meihy, J. C. S. B. (1991). Canto de morte Kaiowá: História oral de vida. São Paulo, SP: Loyola.

Mbembe, A. (2011). Necropolítica. Tenerife: Melusina.

Mondardo, M. (2013). O direito ao território tradicional Guarani-Kaiowá em Mato Grosso do Sul: Insegurança, biopolítica e estado de exceção. São Paulo, SP: NERA- UNESP.

Mondardo, M. (2017). Insecurity territorialities and biopolitical strategies of the Guarani and Kaiowá indigenous folk on Brazil's borderland strip with Paraguay. L'Espace Politique, (31). http://doi.org/10.4000/espacepolitique.4212

Mondardo, M. (2018). Territórios de trânsito: Dos conflitos entre Guarani e Kaiowá, paraguaios e "gaúchos" à produção de multi/transterritorialidades na fronteira. Rio de Janeiro, RJ: Consequência.

Morais, B. M. (2016). Do corpo ao pó: Crônicas da territorialidade Kaiowá e Guarani nas adjacências da morte (Dissertação de mestrado). Departamento de Antropologia, Universidade de São Paulo, São Paulo, SP.

Morgado, A. (1991). Epidemia de suicídio entre os Guarani-Kaiowá: Indagando suas causas eavançando a hipótese do recuo impossível. Cadernos de Saúde Pública, 7(4), 585-598. https://doi.org/10.1590/S0102-311X1991000400009

Nolen, S. (2017). Os esquecidos: por dentro da crise de suicídios indígenas no Brasil. The Globe And Mail, Mundo, America Latina. Recuperado de https://www.theglobeandmail.com/news/world/os-esquecidos-por-dentro-da-crise-de-suicidios-indigenas-no-brasil/article34321173/

Raffestin, C. (1993). Por uma geografia do poder. São Paulo, SP: Ática.

Santos, B. S. (2007). Renovar a teoria crítica e reinventar a emancipação social. São Paulo, SP: Boitempo, 2007.

Zinet, C., Tupinambà, I., \& Cabral, M. (2012). O massacre do povo Guarani Kaiowá. Le Monde Diplomatique Brasil, (54). Recuperado de https:// diplomatique.org.br/o-massacre-do-povo-guarani-kaiowa/ 


\section{Pamela Staliano}

Professora Adjunta do Curso de Graduação e Pós-Graduação em Psicologia da Faculdade de Ciências Humanas da Universidade Federal da Grande Dourados (UFDG), Dourados - MS. Brasil.

(iD https://orcid.org/0000-0002-5868-0702

E-mail: pamelastaliano@ufgd.edu.br

\section{Marcos Leandro Mondardo}

Professor Adjunto do Curso de Graduação e Pós-Graduação em Geografia da Faculdade de Ciências Humanas da Universidade Federal da Grande Dourados (UFDG), Dourados - MS. Brasil.

(iD) https://orcid.org/0000-0001-8862-8801

E-mail: marcosmondardo@yahoo.com.br

\section{Roberto Chaparro Lopes}

Graduando em Psicologia, bolsista de iniciação científica da Faculdade de Ciências Humanas da Universidade Federal da Grande Dourados (UFDG), Dourados - MS. Brasil.

(iD) https://orcid.org/0000-0002-2064-5610

E-mail: robertochaparro10@hotmail.com

Endereço para envio de correspondência:

Universidade Federal da Grande Dourados (UFGD) Rodovia Dourados/Itahum, Km 12 - Unidade II, Caixa Postal: 364, CEP: 79.804-970

Recebido 23/03/2019

Aceito 06/05/2019

Received 03/23/2019

Approved 05/06/2019

Recibido 23/03/2019

Aceptado 06/05/2019

Como citar: Staliano, P., Mondardo, M. L., \& Lopes, R. C. (2019). Onde e como se suicidam os Guarani e Kaiowá em Mato Grosso do Sul: Confinamento, Jejuvy e Tekoha. Psicologia: Ciência e Profissão, 39 (n.spe)., 9-21. https://doi.org/10.1590/1982-3703003221674

How to cite: Staliano, P., Mondardo, M. L., \& Lopes, R. C. (2019). Where and How the Guarani and Kaiowá commit suicide in Mato Grosso do Sul: Confinement, Jejuvy and Tekoha. Psicologia: Ciência e Profissão, 39 (n.spe)., 9-21. https://doi.org/10.1590/1982-3703003221674

Cómo citar: Staliano, P., Mondardo, M. L., \& Lopes, R. C. (2019). ¿Dónde y cómo se suicidan los Guaraníes y Kaiowás en Mato Grosso del Sur: Confinamiento, Jejuvy y Tekoha. Psicologia: Ciência e Profissão, 39 (n.spe)., 9-21. https://doi.org/10.1590/1982-3703003221674 